\section{Racismo institucional e os usos de álcool e outras drogas: uma reflexão bioética}

Ribeiro, Andréa Leite

Doutoranda do Programa de Pós-Graduação em Bioética, da Universidade de Brasília (UnB). Pesquisadora do Observatório da População Negra (Nesp/Ceam-UnB). Bolsista pelo Coordenação de Aperfeiçoamento de Pessoal de Nivel Superior(CAPES). E-mail: aleite1104@gmail.com

\section{Nascimento, Wanderson Flor do}

Professor do Programa de Pós-Graduação em Bioética e do Departamento de Filosofia da Universidade de Brasília $(U n B)$.

PALAVRAS-CHAVE: Drogas; Racismo; Bioética; Saúde.

Reconhecemos que o uso de álcool e outras drogas (AD) é fenômeno constante na história da humanidade. Do mesmo modo, devemos reconhecer que o passado escravagista do Brasil produziu efeitos no modelo organizacional da sociedade, com hierarquização de grupos sociais devido a sua cor, cultura ou origem étnica. A construção social quanto ao negro, no Brasil, no período pós abolição enquanto uma ameaça a sociedade, esta diretamente relacionada com o racismo que os/as negros/as são submetidos ao buscar um serviço de saúde. Ser negro e usuário de drogas, especialmente as ilegais, no Brasil, significa que os processos e procedimentos de saúde destinados a eles por vezes são discriminatórios e negligentes, sendo um problema de saúde pública concernente a reflexão bioética. Objetivase aqui analisar desde uma perspectiva bioética cunhada na América Latina, como o racismo institucional afeta a saúde física e psíquica das pessoas, podendo repercutir na relação dos humanos com as drogas. Como método, foram realizadas análises e reflexões de estudos bibliográficos e documentais sobre racismo institucional, políticas sobre drogas, acessibilidade e responsividade do sistema de saúde, redução de riscos e danos (RD) e Bioética. Dos achados foi possível identificar que a política de drogas tem um efeito nocivo para as pessoas negras, com desqualificação do seu sofrimento mental, não responsividade do serviço de saúde, baixa qualidade da atenção em saúde, aumento de encarceramento e genocídio desse mesmo grupo populacional, demandando a compreensão de que o aspecto racial atravessa as intervenções em saúde destinada aos negros. A análise da aplicação da atual política de álcool e outras drogas aponta que essa não vem produzindo efeitos positivos, especialmente entre os que estão em condição de vulnerabilidade. A compreensão da contribuição da bioética para o sistema de saúde, pode favorecer a equidade, a justiça social e ações antirracistas e igualitárias, podendo assim repercutir positivamente na vida daqueles que buscam os serviços de saúde. Espera-se que das discussões, os participantes compreendam a relação entre a política de drogas e o racismo institucional, podendo perceber e atuar na modificação de práticas racistas frente aos usuários no SUS. A história da política de drogas no Brasil, passou por modificações passando a compreender o sofrimento devido ao uso prejudicial de álcool e outras drogas enquanto um problema a ser tratado pelo sistema de saúde e não pelo sistema de justiça e os conceitos de clínica ampliada, autonomia, $\mathrm{RD}$, foi incorporada as estratégias da política. No entanto, a prática vem se distanciando desses conceitos pilares para uma intervenção não manicomial, excludente e das evidências científicas e se aproximando das práticas autoritárias e da ideologia manicomial e excludente. O resultado da política pautada na guerra as drogas, vem se revelando enquanto guerra as pessoas que fazem uso de drogas, tendo como perfil os jovens negros e as pessoas mais vulneráveis sendo emergente a ampliação de discussão e compreensão do fenômeno, para a modificação de práticas higienistas, segregadoras e promotoras de exclusão social e iniquidade.

AGRADECIMENTO: A Coordenação de Aperfeiçoamento de Pessoal de Nível Superior (CAPES).

\section{REFERÊNCIAS}

[1] BASTOS, F; BERTONI, N. organizadores. Pesquisa nacional sobre o uso de crack. Quem são os usuários de crack e/ou similares do Brasil? Quantos são nas capitais brasileiras?. Rio de Janeiro: Editora ICICT/Fiocruz; 2014.

[2] NERY FILHO, A. Por que os humanos usam drogas? In: Nery Filho A, Valério, ALR, organizadores. Módulo para capacitação dos profissionais do projeto consultório de rua. Brasília/Salvador: SENAD/CETAD, 2010. p. 11-16.

[3] OLIVEIRA, F. Condición socioeconómica, de género y raza/etnia en las investigaciones biomédicas. In: Keyeux G, Penchaszadeh V, Saada A, coordenadores. Ética de la investigación en seres humanos y políticas de salud pública. Bogotá: UNESCO, Red Latinoamericana y del Caribe, Universidad Nacional de Colombia, Instituto de Genética; 2006. p. 63-86.

[4] BENEDITO, D. Do Ferro ao aço: Racismo, maus tratos, tortura, descaso! Ofícios da dignidade!.In. Relatório Anual 2016-2017/Mecanismo Nacional de Prevenção e Combate à Tortura; Organização: Mecanismo Nacional de Prevenção e Combate à Tortura. - Brasília, 2016.

[5] BRASIL. Ministério da Saúde. Secretaria de Gestão Estratégica e Participativa. Departamento de Apoio à Gestão Participativa. Política Nacional de Saúde Integral da População Negra: uma política para o SUS /Ministério da Saúde, Secretaria de Gestão Estratégica e Participativa, Departamento de Apoio à Gestão Participativa. - 2. ed. Brasília: Editora do Ministério da Saúde, 2013. 